\title{
Formation of Sigma Phase in the Mn-Mo System
}

\author{
by B. F. Decker, R. M. Waterstrat, and J. S. Kasper
}

$\mathrm{T}$ $\mathrm{HE}$ existence of $\sigma$ phase in the Mn-Mo system was discovered in this laboratory several years ago, ${ }^{1}$ but neither the conditions of its formation nor its composition were known, and preliminary attempts to reproduce the phase were unsuccessful. We wish now to specify the information appropriate to $\sigma$ phase formation on the basis of experiments performed since that time.

The starting materials were in every case electrolytic manganese and high purity molybdenum. Two methods of preparation were employed: 1-arcmelting varying combinations of the elements in an inert atmosphere and subsequent heat treating, and 2 -sintering compressed mixtures of finely divided powders of the elements. In the latter method, the powders were first passed through 200 mesh screen and then compressed into cylinders of $3 / 8$ in. diameter and $1 / 2$ in. length, which were sintered at elevated temperatures in an atmosphere of dry hydrogen. For some samples, the sintering temperature was $1200^{\circ} \mathrm{C}$ (for $1 \mathrm{hr}$ ), and these were then heat-

Table I. Results Obtained from Samples Produced by Sintering Compressed Mixtures

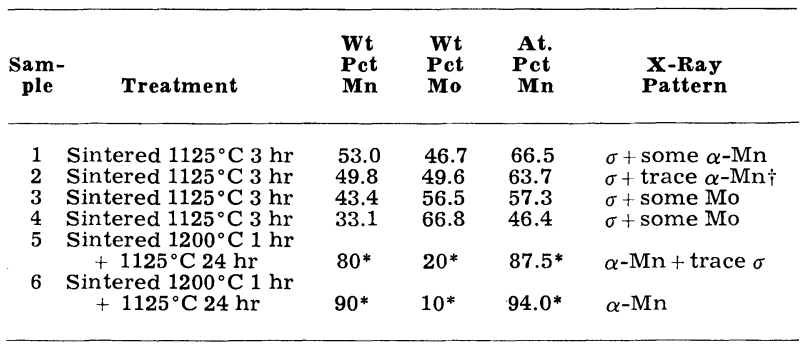

* Nominal starting composition

† Only evidence for $\alpha$-Mn is one very weak line.

treated at lower temperatures for times up to $24 \mathrm{hr}$. Eventually it was found, for the proper composition, that essentially pure $\sigma$ phase could be produced by sintering at $1125^{\circ} \mathrm{C}$ for $3 \mathrm{hr}$. Quenching to room temperature was effected by means of a stream of cold, dry hydrogen in a water-cooled chamber.

The arc-melting procedure was found to be unsatisfactory after an investigation of many samples at different compositions and temperatures. Large quantities of manganese were vaporized during melting and none of the products were homogeneous or contained extended regions of pure $\sigma$ phase. Nonetheless, these experiments established that no $\sigma$ formation occurs in the Mn-Mo system below $1115^{\circ} \mathrm{C}$, and indicated, at least roughly, the composition range of interest for further exploration.

The more definite results obtained from samples produced by the second method are given in Table I.

B. F. DECKER, R. M. WATERSTRAT, and J. S. KASPER are associated with the Metallurgy Research Dept., Research Laboratory, General Electric Co., Schenectady.

TN 196E. Manuscript, Aug. 24, 1953.
Table II. X-ray Powder Pattern for Mn-Mo Sigma (64 Atomic Pct Mn). Crystal system, tetragonal $a_{0}=9.10, c_{0}=4.74 \AA$. $\mathrm{Cr} \mathrm{K} \alpha$ radiation.

\begin{tabular}{|c|c|c|c|c|}
\hline \multicolumn{3}{|c|}{ Mn-Mo $\sigma$} & \multicolumn{2}{|c|}{ Fe-Mo $\sigma^{3}$} \\
\hline$h k l$ & $d$ & $I^{*}$ & $d$ & $I^{*}$ \\
\hline 311 & 2.463 & $\mathrm{~m}$ & 2.46 & w \\
\hline 002 & 2.368 & $\mathrm{~m}$ & 2.35 & $\mathrm{mw}$ \\
\hline 410 & 2.205 & $\mathbf{s}$ & 2.21 & $\mathrm{~s}$ \\
\hline 330 & 2.144 & $\mathrm{~ms}$ & $\overline{2} .13$ & $\mathrm{~m}$ \\
\hline 202 & 2.097 & $\mathrm{~ms}$ & 2.08 & $\mathrm{~m}$ \\
\hline 212 & 2.045 & $\mathrm{~s}$ & 2.04 & $\mathrm{~ms}$ \\
\hline 411 & 2.000 & vs & 1.99 & $\mathbf{s}$ \\
\hline 331 & 1.952 & $\mathrm{~s}$ & 1.93 & $\mathrm{~m}$ \\
\hline 222 & 1.907 & $\mathrm{mw}$ & 1.90 & $\mathrm{w}$ \\
\hline 312 & 1.829 & $\mathrm{mw}+$ & 1.82 & $\mathbf{w}$ \\
\hline 431,501 & 1.697 & vvw & & \\
\hline 511 & 1.672 & vvw & & \\
\hline 432 & 1.444 & $\mathrm{mw}$ & 1.44 & vw \\
\hline 611,512 & 1.426 & $\mathrm{mw}$ & 1.43 & $\mathrm{mw}$ \\
\hline 313 & 1.385 & vw & & \\
\hline 621,522 & 1.377 & $\mathrm{~ms}$ & 1.37 & $\mathrm{~m}$ \\
\hline 541 & 1.362 & vvw & & \\
\hline 532,631 & 1.304 & $\mathrm{~s}$ & 1.30 & $\mathrm{~ms}$ \\
\hline $413,550,710$ & 1.286 & vs & & \\
\hline 602 & 1.279 & $\mathrm{~m}$ & & \\
\hline 333 & 1.272 & $\mathrm{~ms}$ & 1.28 & $\mathbf{s}$ \\
\hline 612 & 1.267 & $\mathrm{~m}$ & & \\
\hline 701,720 & 1.253 & $\mathbf{s}$ & & \\
\hline 551,711 & 1.244 & $\mathrm{~m}$ & 1.246 & $\mathrm{mw}$ \\
\hline 622 & 1.232 & $\mathrm{mw}$ & & \\
\hline 542,641 & 1.221 & $\mathrm{mw}$ & 1.220 & $\mathrm{~m}$ \\
\hline 721 & 1.211 & $\mathrm{~ms}$ & & \\
\hline 433,503 & 1.195 & vvw & 1.205 & $\mathbf{w}$ \\
\hline 004 & 1.187 & $\mathrm{~s}$ & 1.177 & $\mathrm{~m}$ \\
\hline
\end{tabular}

* w, weak; mw, medium weak; vw, very weak; vvw, very, very weak; $\mathrm{m}$, medium; ms, medium strong; $\mathrm{s}$, strong; vs, very strong.

A portion of sample 2 heated for $16 \mathrm{hr}$ at $1000^{\circ} \mathrm{C}$ in a Vycor tube transformed to molybdenum plus unidentified phases of complex X-ray pattern.

From these few results it appears that the region of $\sigma$ phase is quite narrow in composition. It is of interest that the composition is such as to make for difficulties in correlating this structure on an electron atom basis with other $\sigma$ structures of iron, cobalt, and nickel. In that respect Mn-Mo shows the same anomaly as $\mathrm{Mn}-\mathrm{Cr}$ and $\mathrm{Mn}-\mathrm{V}$ systems. ${ }^{2}$ A second feature is that in common with the two other known molybdenum $\sigma$ 's (Fe-Mo and Co-Mo), MnMo $\sigma$ exists only at elevated temperatures.

The X-ray powder pattern of the pure $\sigma$ phase of Mn-Mo is given in Table II. It agrees well with the patterns established for other $\sigma$ structures, especially with that for Fe-Mo $\sigma$ as given by Goldschmidt. ${ }^{3}$ An attempt is being made to establish whether an ordering of the respective atoms occurs and such information will be reported in a future publication.

\section{Acknowledgment}

The authors acknowledge gratefully the assistance of Mrs. J. R. Belanger in some portions of this work.

\section{References}

${ }^{1}$ J. S. Kasper, B. F. Decker, and J. R. Belanger: Journal of Applied Physics (1951) 22, p. 361.

${ }^{2}$ A. H. Sully: Journal Inst. Metals (1951) 80, p. 173.

${ }^{3}$ H. J. Goldschmidt: Research (1949) 2, p. 343. 